\title{
Pengembangan dan Implementasi Aplikasi Pengawasan Ternak Berbasis Android di Peternakan Bukit Aren Farm Majalengka
}

\author{
Faraj $^{1)}$, Adian Fatchur Rochim ${ }^{2)}$, Rinta Kridalukmana ${ }^{2)}$ \\ Program Studi Sistem Komputer, Fakultas Teknik, Universitas Diponegoro \\ Jalan Prof. Sudharto, Tembalang, Semarang, Indonesia
}

\begin{abstract}
Bukit Aren Farm located in Majalengka, West Java is a company specialized in the broiler of the agriculture industry, farming broiler performed in different places and every breeding cattle carried monitored by the supervisory staff. Every day, staf record information manually about the animal in the cage that data will be used as a performance evaluation of animal production. The livestock management personnel encountered problems when running calculations of the evaluation product and efficiency livestock because the calculation process can be done if the existing data stored carefully and systematically, in particular the data recorded cattle in significant quantities, it would require much time for staff supervision to determine the level of production performance.

Application developed using waterfall method. The waterfall model is composed of: requirements, design, implementation, verification, maintenance. To begin the design steps required observations or interviews to determine the needs of the system under design. Applications developed using CodeIgniter framework, angularjs and ionic based architecture.

Results of the project is the application mobile livestock monitoring data storage that can serve the number of deaths, data on the number quarantine of chicken, and the amount of data that then feed use these data will generate a data value prices and feed consumption levels of livestock mortality information for the evaluation process in the livestock in line with the business processes of Bukit Aren Farm. The application has been tested by using black box method and the results of these tests indicate that all functions in the system has been well running on the Android operating system from version 4.1 .
\end{abstract}

Keywords: Android, Mobile, Application, CodeIgniter, Ionic, Laravel, AngularJS.

\section{PENDAHULUAN}

$\mathrm{B}$ ukit Aren Farm merupakan perusahaan yang bergerak di bidang industri budidaya ayam broiler dan kemitraan, berlokasi di Jalan Pasukan Sindangkasih No. 7 Majalengka, Jawa Barat.

Kegiatan budidaya ayam broiler dilakukan di berbagai lokasi yang berbeda, semua informasi tenak dari setiap lokasi dicatat secara manual sebagai laporan harian dari kegiatan budidaya ternak.
Proses pencatatan yang dilakukan oleh staf pengawasan ternak merupakan salah satu kegiatan utama yang dilakukan, pengawasan ternak dimulai dari kegiatan pengawasan langsung ke lokasi kandang dan hasil catatan informasi yang setiap harinya diperoleh dari setiap lokasi kandang. Informasi yang terkumpul kemudian diolah yang nantinya akan diperoleh informasi antara lain mengenai : mortalitas, morbilitas, feed convertion ratio (FCR), usia ternak dan jumlah konsumsi pakan. Upaya pengolahan informasi ini untuk setiap kandang yang membutuhkan usaha yang tidak sedikit. Perubahan metode dari pencatatan pada kertas ke bentuk digital bisa menjadi metode alternatif untuk memecahkan masalah yang terjadi. Pengembangan sistem informasi sebagai sarana pencatatan laporan ternak secara digital dapat mengurangi tenaga yang dibutuhkan secara signifikan, mempercepat pengolahan informasi ternak dan mengurangi kesalahan pengolahan informasi.

Perangkat lunak komputer dapat dijadikan alternatif untuk mengintegrasikan proses manajemen dan pengawasan pada perusahaan peternakan Bukit Aren Farm. Sebagai contoh, pencatatan data informasi ternak dapat dilakukan di dalam sebuah perangkat lunak sehingga lebih mempercepat proses pengolahan data.

Salah satu alternatif solusi dari permasalahan tersebut adalah perangkat lunak yang berupa perangkat lunak mobile. Perangkat lunak ini akan digunakan oleh staf pengawasan yang nantinya digunakan intuk melakukan manajemen dan monitoring ternak. Pada perangkat lunak ini juga tersedia fitur input informasi ternak dari setiap kandang yang langsung terintegrasi dengan server sehingga akan mempercepat proses rekapitulasi data. Perangkat bergerak yang akan digunakan adalah jenis ponsel pintar dengan sistem operasi Android, maka aplikasi manajemen pengawasan tersebut harus dirancang agar dapat dijalankan pada platform Android.

\section{LANDASAN TEORI}

A Penelitian Sebelumnya

Sebelum melakukan pengembangan sistem diperlukan beberapa studi literatur untuk mengetahui efektivitas penggunaan sistem informasi pada peternakan.

Muhammad Risal Fatoni [1] pada tahun 2011 berpendapat bahwa sistem pemantauan perkembangan ayam broiler dapat melakukan proses pencatatan dan menghasilkan perhitungan indeks produksi untuk mengetahui hasil kerja (kinerja produksi) yang dilakukan oleh peternak.

Cisde Mulyadi [2] dari hasil penelitian yang dilakukan bahwa sistem informasi peternakan ayam potong berbasis web yang dapat digunakan untuk mengelola data-data produksi dan 
pemasaran ayam potongnya, aplikasi notifikasi sms untuk mengingatkan peternak tentang tata laksana pemeliharaan yang harus dilaksanakan besok, dan aplikasi sistem pendukung keputusan untuk membantu peternak memantau pemeliharaan ternaknya berdasarkan analisis pakan masuk, bobot, dan feed convertion ratio serta membantu peternak dalam pengambilan keputusan penjualan ayam berdasarkan analisis harga pasar dan harga produksi ayam.

\section{B Sistem Informasi}

Sistem adalah entitas atau satuan yang terdiri dari dua atau lebih komponen atau subsistem (sistem yang lebih kecil) yang saling terhubung dan terkait untuk mencapai satu tujuan. Informasi merupakan fakta yang memiliki arti sehingga memungkinkan untuk dimanfaatkan. Sedangkan semua fakta tersebut yang tercatat, terekam atau terdokumentasikan disebut data.

Alter [3] berpendapat untuk sistem informasi sebagai tipe khusus dari sistem kerja. Sistem kerja adalah suatu sistem di mana manusia dan/atau mesin melakukan pekerjaan dengan menggunakan sumber daya untuk memproduksi produk tertentu dan/atau jasa bagi pelanggan. Sistem informasi adalah suatu sistem kerja yang kegiatannya ditujukan untuk pengolahan (menangkap, transmisi, menyimpan, mengambil, memanipulasi dan menampilkan) informasi. Contoh sistem informasi yang mudah ditemui adalah Sistem Penjualan Toko, Sistem Informasi Akademik dan Sistem Tagihan Listrik.

\section{Sistem Basis Data}

Data merupakan fakta yang tercatat atau terekam. Segala sesuatu dapat dijadikan data namun data tersebut tidak selalu bermanfaat untuk dikumpulkan. Sebuah data mentah yang baru saja didapatkan bisa saja tidak memiliki arti sama sekali, tetapi setelah diolah data tersebut bisa menjadi informasi yang membantu proses bisnis. Data perlu dikumpulkan data sudah dilakukan sejak ribuan tahun lalu dengan menulis. Sekarang data disimpan dan dikumpulkan dengan bantuan komputer, kumpulan atau koleksi ini dikenal dengan basis data.

Menurut Fathansyah [4] sistem basis data merupakan sistem yang terdiri atas kumpulan tabel data yang saling berhubungan (dalam sebuah basis data di sebuah komputer) dan sekumpulan program (yang biasa disebut Data Base Management System) yang memungkinkan beberapa pemakai dan/atau program lain untuk mengakses dan memanipulasi tabel data tersebut. Contoh dari Data Base Management System antara lain SQL Server, MySQL, Oracle dan DB2.

D Kerangka Kerja CodeIgniter

Codeigniter adalah sebuah framework bahasa pemrograman PHP. Codeigniter diperkenalkan kepada public pada tanggal 28 Februari 2008. Codeigniter menawarkan kemudahan serta standarisasi dalam proses pengembangan website dan aplikasi berbasis web. Dengan Codeigniter proses pengembangan website menjadi lebih cepat dan terstandar. Standar ini sangat berguna dalam pengembangan website yang dikerjakan oleh tim. Codeigniter juga telah menyediakan library dan helper yang berguna dan mempermudah proses development. Terdapat beberapa kelebihan penggunaan Codeigniter dalam pengembangan suatu proyek, yaitu : 1.Menghemat Waktu 2.Code Reuse 3.Dukungan Komunitas 4.Kumpulan Best Practice Codeigniter dibangun menggunakan konsep Model-View-Controller development pattern, yaitu sebuah teknik pemrograman yang memisahkan logika bisnis, logika data, dan logika presentasi [5].

\section{E Kerangka Kerja Ionic}

Ionic [6] adalah kerangka kerja Mobile HTML5 untuk mengembangkan aplikasi perangkat bergerak lintas-platform hybrid native menggunakan HTML, JavaScript dan CSS.
Ionic dikembangkan untuk memudahkan pengembang mengembangkan aplikasi perangkat bergerak hybrid native daripada membuat situs perangkat bergerak. Ionic merupakan kerangka kerja yang fokus pada interaksi dengan pengguna melalui HTML5 tetapi dengan kecepatan aplikasi native. Ionic tidak menggunakan kerangka kerja CSS Bootstrap maupun library JavaScript jQuery mobile melainkan menggunakan kerangka kerja JavaScript angularJS yang mempunyai kecepatan proses lebih cepat dari jQuery mobile.

\section{PERANCANGAN SISTEM}

\section{A Analisis Kebutuhan}

Penyusunan analisis kebutuhan dilakukan untuk mengurangi risiko sistem gagal dikembangkan. Kegagalan pengembangan sistem umumnya terjadi karena sistem tidak memenuhi kebutuhan pengguna atau sistem tidak sesuai dengan proses bisnis yang berjalan. Studi kelayakan perlu dilakukan dalam penyusunan analisis kebutuhan untuk menghindari risiko tersebut. Studi kelayakan dapat dilakukan dengan cara wawancara, observasi dan membaca dokumen. Hasil analisis kebutuhan berupa dokumen System Requirements Specifications (SRS). Pengembangan ini menggunakan struktur SRS tersebut untuk menyampaikan analisis kebutuhan.

1) Kondisi Awal

Proses selama wawancara dan observasi memberikan gambaran kondisi yang terjadi dilapangan. Pada proses pengawasan ternak, terdapat beberapa aktivitas yang harus dilakukan. Gambar 1 Menunjukan flowchart aktifitas kondisi awal proses pengawasan ternak.

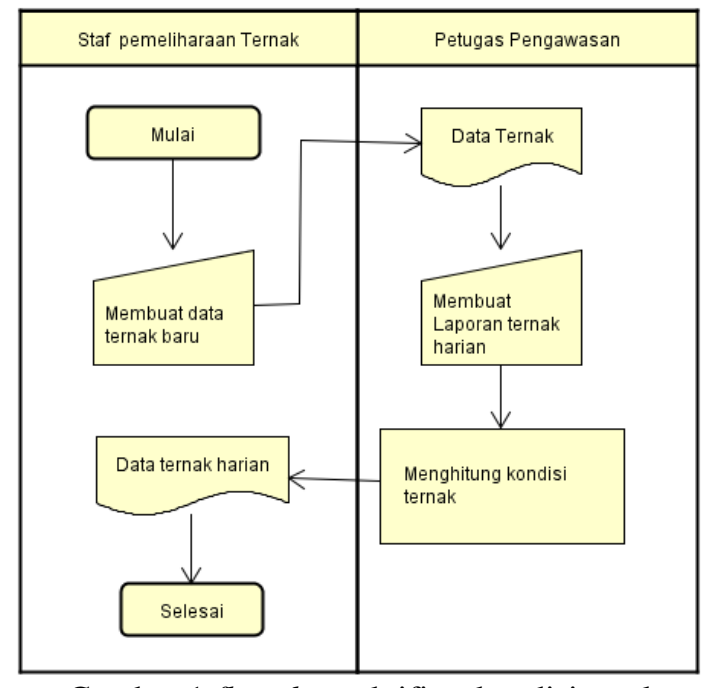

Gambar 1 flowchart aktifitas kondisi awal

Penjelasan pada flowchart diatas adalah sebagai berikut :

1. Staf pemeliharaan ternak membuat informasi ternak baru, data yang dibuat berisi informasi tanggal ternak, jensi doc, bobot doc, alamat dan nomor kandang, jumlah populasi ternak, jumlah stok pakan awal, dan petugas tenaga produksi kandang.

2. Staf pemeliharaan ternak memberikan informasi ternak baru ke staf pengawasan ternak untuk dilakukan proses pengawasan ternak.

3. Staf pengawasan ternak mencatat informasi ternak harian dari hasil pengawasan ternak, data informasi yang diperoleh diantaranya mortalitas, morbilitas, bobot ratarata ternak, jumlah konsumsi pakan ternak.

4. Staf pengawasan ternak mengolah informasi ternak, informasi yang diperoleh berupa FCR (Feed Convertion Ratio), dan tingkat kematian ternak. 
5. Staf pengawsan ternak memberikan hasil laporan pengawasan ternak ternak harian kepada staf divisi pemeliharan.

Pembuatan SRS dapat dilakukan setelah data yang dikumpulkan pada kondisi awal sudah cukup menjelaskan keadaan sebelum sistem dikembangkan.

\section{2) Deskripsi Umum Sistem}

Deskripsi umum sistem diperlukan untuk menjelaskan perspektif produk akhir hasil pengembangan, fungsi produk yang diharapkan untuk berjalan, kelompok pengguna, lingkungan pengoperasian serta lingkungan pengguna yang akan menggunakan sistem.

\section{Perspektif Produk Akhir}

Produk pengembangan adalah aplikasi yang dapat digunakan oleh peternakan Bukit Aren Farm dalam melakukan manajemen pengawasan ternak. Aplikasi tersebut digunakan untuk mengelola data aktivitas pengawasan ternak.

2. Fungsi Produk

Aplikasi dapat menyimpan data laporan ternak. Pengolahan dapat dilakukan lebih cepat menggunakan komputer. Data yang disimpan dalam sistem dapat diolah untuk menghasilkan laporan.

\section{Kelompok Pengguna}

Pengguna yang menggunakan sistem ini terdiri dari 2 jenis, yaitu : pengguna operator atau staf manajemen ternak dan pengguna staf pengawasan ternak atau petugas pengawasan. Kedua pengguna tersebut memiliki aktivitas yang berbeda dalam menggunakan sistem.

a. Pengguna operator adalah pengguna yang bertugas melakukan pengelolaan terhadap pengguna staf pengawasan ternak, dan data ternak.

b. Pengguna staf pengawasan ternak adalah pengguna yang melakukan aktivitas pencatatan informasi ternak. Pengguna staf pengawasan ternak adalah pengguna yang merupakan karyawan dari Bukit Aren Farm yang melakukan pengawasan ternak.

4. Lingkungan Pengoperasian

Aplikasi dioperasikan di Bukit Aren Farm. Bukit Aren Farm menggunakan koneksi internet dalam mengoperasikan aplikasi. Aplikasi bisa digunakan sepanjang hari selama server dan jaringan tidak mengalami gangguan.

5. Lingkungan Pengguna

Pada sisi operator aplikasi berupa aplikasi berbasis web. Pengguna bisa mengakses sistem melalui web browser dari perangkat komputer atau tablet, sedangkan pada sisi pengguna staf pengawasan ternak aplikasi berupa aplikasi ponsel pintar yang telah dipasang sebelumnya.

3) Kebutuhan Fungsional

Sistem yang dikembangkan diharapkan dapat memenuhi kebutuhan fungsional agar dapat digunakan sesuai dengan proses bisnis yang telah berjalan pada sisi operator dan pengguna staf pengawasan ternak di Bukit Aren Farm. Berikut adalah kebutuhan fungsional yang harus dipenuhi oleh sistem.

1. Sistem pada sisi operator dapat menyimpan, mengubah dan menghapus data ternak dengan nomor indeks ternak. Fungsi tersebut bertujuan agar data ternak yang masuk secara otomatis tercatat sebagai data ternak atas nomor indeks ternak yang dimaksud.

2. Sistem pada sisi operator dapat menyimpan, mengubah dan menghapus data kandang yang digunakan atribut ternak dengan nomor indeks kandang. Fungsi tersebut bertujuan agar memenuhi ketersediaan informasi kandang.
3. Sistem pada sisi operator dapat menyimpan, mengubah dan menghapus data pakan yang digunakan atribut ternak dengan nomor indeks pakan. Fungsi tersebut bertujuan agar memenuhi ketersediaan informasi pakan.

4. Sistem pada sisi operator dapat menyimpan, mengubah dan menghapus data petugas staf pengawasan ternak yang digunakan atribut ternak dengan nomor indeks petugas. Fungsi tersebut bertujuan agar staf petugas pengawasan dapat menyimpan informasi ternak sesuai dengan indeks ternak yang dimilikinya.

5. Sistem pada sisi operator dapat mengolah data ternak sesuai dengan urutan waktu ternak dan kondisi (state) yang dimiliki oleh ternak tersebut.

6. Sistem pada sisi operator dapat melihat laporan ternak secara bulanan maupun periodik.

7. Sistem pada sisi staf pengawasan ternak dapat menyimpan informasi ternak sesuai nomor index ternak yang dimilikinya.

8. Sistem pada sisi staf pengawasan ternak dapat melihat informasi ternak sesuai nomor index ternak yang dimilikinya. Fungsi ini bertujuan agar staf dapat melihat informasi ternak berupa informasi periodik sebagai upaya pengawasan ternak yang dilakukan.

9. Sisi pada staf pengawasan ternak dapat menyimpan dan menghapus data catatan sesuai indeks nomor pegawai yang dimilikinya. Fungsi ini bertujuan agar staf petugas pengawasan dapat menyimpan catatan dari hasil pengawasan yang dilakukan.

4) Kebutuhan Non-Fungsional

Selain kebutuhan fungsional sistem juga harus memenuhi kebutuhan non-fungsional agar sistem yang berjalan dapat digunakan dengan baik oleh pengguna pada sisi operator Bukit Aren Farm maupun sisi pengguna staf pengawasan ternak Bukit Aren Farm. Berikut merupakan kebutuhan fungsional yang harus dipenuhi oleh sistem.

1. Operasional

a. Sistem yang bekerja pada operator Bukit Aren Farm dapat diakses dari perangkat komputer dan tablet.

b. Sistem memiliki fitur pemberitahuan pesan kesalahan muncul jika pengguna melakukan kesalahan pemakaian sistem.

c. Sistem dapat memperbarui data secara otomatis.

2. Keamanan

a. Sistem memiliki fungsi login untuk memberikan akses ke pengguna.

b. Sistem memiliki fungsi role untuk membedakan hak pengguna.

c. Sistem mengimplementasikan metode soft delete untuk menjaga validasi pengolahan data

B Desain Sistem

SRS yang dihasilkan dari analisis kebutuhan digunakan sebagai bahan perancangan sistem. Kebutuhan fungsional di dalam SRS menentukan bagaimana sistem harus dibangun sehingga mampu memenuhi kebutuhan yang diharapkan. Spesifikasi teknis dibuat pertama kali dalam perancangan untuk menetapkan lingkungan pengembangan. Pemodelan dilakukan setelah spesifikasi sistem selesai ditentukan. Penulisan kode belum bisa dimulai sebelum pemodelan selesai dibuat. Penulisan kode tanpa memperhatikan pemodelan akan menimbulkan risiko kegagalan pengembangan. Desain antarmuka dilakukan setelah pemodelan selesai dibuat sehingga sistem mampu dioperasikan pengguna dengan mudah. Pengembangan aplikasi yang mengabaikan desain antarmuka user friendly cenderung susah digunakan. 
1) Spesifikasi Teknis

1. Arsitektur Sistem

Sistem yang dikembangkan berupa aplikasi berbasis web dan aplikasi ponsel pintar. Web server dibutuhkan untuk menjalankan aplikasi tersebut. Data yang diolah sistem disimpan pada basis data. Server basis data juga dibutuhkan untuk menjalankan basis data yang digunakan sistem. Admin Bukit Aren Farm dapat mengakses sistem melalui web browser dengan cara memanggil URL aplikasi.

Web Server dan basis data berada pada cloud yang didukung oleh IaaS DigitalOcean. Admin Bukit Aren Farm dapat mengakses sistem melalui browser sedangkan petugas diharuskan memasang aplikasi perangkat bergerak pada ponselnya.

2. Arsitektur Aplikasi

Deskripsi umum SRS menjelaskan bahwa sistem berupa aplikasi web pada sisi admin Bukit Aren Farm dan aplikasi perangkat bergerak pada petugas Bukit Aren Farm. Arsitektur yang digunakan untuk membangun aplikasi tersebut adalah Restful. Bahasa yang dipakai adalah PHP dengan kerangka kerja Laravel 4.2, Javascript dengan kerangka kerja AngularJS dan Ionic.

3. Kebutuhan Perangkat Keras

Sistem berjalan dengan posisi server berada di cloud dengan dukungan IaaS sebagai penyedia platform dan infrastruktur. Dengan arsitektur tersebut maka kebutuhan perangkat keras untuk server dapat sepenuhnya diabaikan untuk dapat mendukung platform yang akan dikembangkan.

Sedangkan untuk sisi operator Bukit Aren Farm memerlukan PC yang dapat menjalankan web browser, dari berbagai macam kebutuhan minimal web browser, maka perangkat keras yang dibuhkan pada sisi admin dengan alah sebagai berikut :

- Prosesor: Intel Pentium 4

- $\quad$ RAM : $512 \mathrm{MB}$

- HDD : 4 GB

Untuk sistem yang berjalan pada pengguna petugas pengawasan ternak Bukit Aren Farm memerlukan perangkat bergerak dengan spesifikasi minimal RAM 512 MB.

4. Kebutuhan Perangkat Lunak

Aplikasi membutuhkan perangkat lunak pendukung agar aplikasi bisa berjalan di server. Kebutuhan minimal perangkat lunak server adalah :

- Ubuntu 12.04

LAMP Stack Server

Operator Bukit Aren Farm juga memerlukan perangkat lunak pendukung untuk bisa mengakses aplikasi.Kebutuhan minimal perangkat lunak operator Bukit Aren Farm adalah Web Browser dengan dukungan Javascript. Perangkat yang digunakan oleh petugas pengawasan ternak Bukit Aren Farm juga memerlukan perangkat lunak pendukung untuk bisa menggunakan aplikasi yang dikembangkan. Kebutuhan minimal perangkat lunak petugas pengawasan ternak Bukit Aren Farm adalah menggunakan Sistem Operasi Android versi 4.1 disesuaikan dengan kebutuhan minimal kerangka kerja Ionic yang digunakan untuk mengembangkan sistem.

\section{2) Desain ERD}

Sistem yang dikembangkan merupakan sistem yang berfungsi untuk mengolah data. Pemodelan perlu dilakukan untuk menentukan data yang diolah. Pemodelan tersebut dilakukan setelah spesifikasi teknis ditentukan. ERD digunakan untuk memodelkan data yang akan disimpan dalam basis data.
Langkah yang dilakukan dalam merancang ERD adalah menentukan entitas yang ada, lalu entitas tersebut dihubungkan dalam notasi diagram.

1. Menentukan Entitas

Entitas dapat ditentukan dari SRS. Kebutuhan yang dijelaskan memberikan gambaran data-data yang diolah. Data tersebut merupakan entitas yang akan digunakan dalam merancang ERD. Tabel 1 menunjukkan entitas yang telah ditentukan.

Tabel 1 Tabel Entitas ERD

\begin{tabular}{|l|l|l|}
\hline No & Nama & Keterangan \\
\hline 1. & laporan & Data ternak \\
\hline 2. & laporan_sop & Data sop pada setiap laporan \\
\hline 3. & kandang & Data kandang yang dimiliki \\
\hline 4. & note & Data catatan petugas \\
\hline 5. & pakan & $\begin{array}{l}\text { Data jenis pakan yang } \\
\text { dimiliki }\end{array}$ \\
\hline 6. & perusahaan & $\begin{array}{l}\text { Data perusaaan penyedia } \\
\text { DOC }\end{array}$ \\
\hline 7. & petugas & Data petugas \\
\hline 8. & sop & Data sop \\
\hline 9. & strain & Data strain dari perusahaan \\
\hline
\end{tabular}

\section{Menggambar Diagram}

Diagram dapat digambarkan setelah seluruh entitas didefinisikan beserta atributnya. Tujuan dari diagram adalah menjelaskan hubungan antara entitas yang telah ditentukan. Relasi yang digambarkan dapat diperjelas dengan menambahkan informasi kardinalitas antara entitas.

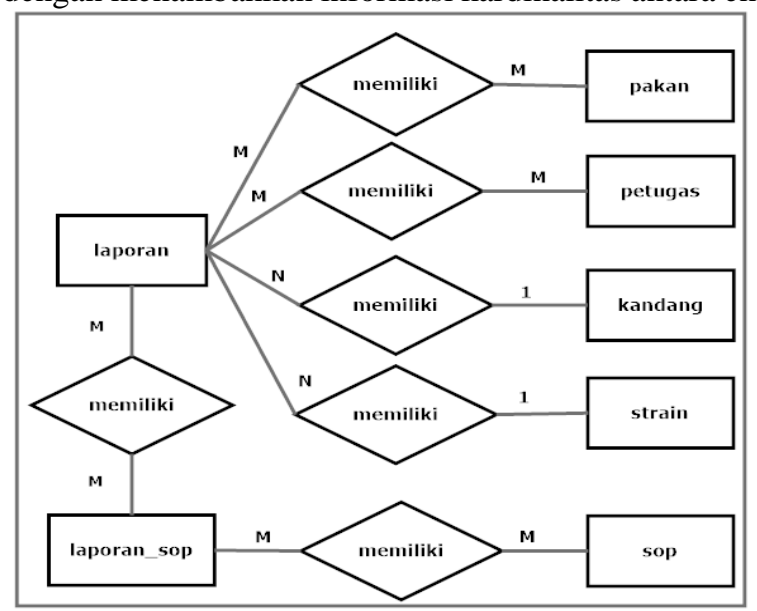

Gambar 2 Diagram ERD Keseluruhan Sistem

Diagram yang menggambarkan keseluruhan sistem tersebut dapat menjelaskan semua data yang diolah sistem. Gambar 1 Menunjukkan ERD keseluruhan sistem.

3) Desain UML

Fungsi yang ditunjukkan pada SRS belum memiliki detail yang cukup untuk dikembangkan. Pemodelan UML memberikan ruang untuk mengembangkan detail fungsi yang dibutuhkan oleh sistem sebelum penulisan kode dimulai. Kesalahan yang dilakukan pada pemodelan akan lebih mudah dianalisis dan diperbaiki daripada saat sistem sudah ditulis dengan bahasa pemrograman.

1. Diagram Aktivitas Sistem

Diagram aktivitas dibuat untuk menggambarkan aliran kerja pada sistem baru untuk menggantikan sistem yang lama. Proses bisnis sistem ini dimulai ketika operator membuat header laporan ternak dan berakhir setelah operator mengubah status ternak pada header laporan ternak. 


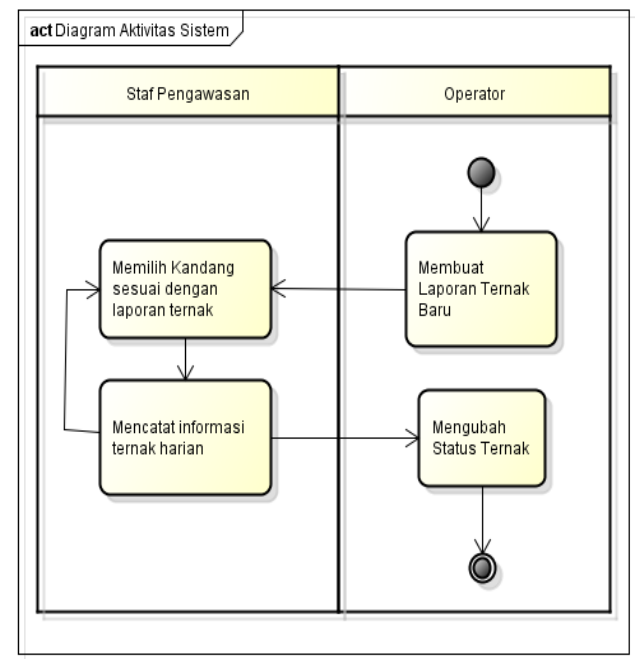

Gambar 3 Diagram Aktivitas Sistem

2. Diagram Use Case Sistem

Bagaimana pengguna menggunakan sistem dapat digambarkan dengan diagram use case. Diagram use case dibuat berdasarkan skenario yang dilakukan pengguna ketika menggunakan fungsi sistem. Diagram use case terlihat pada Gambar 4.

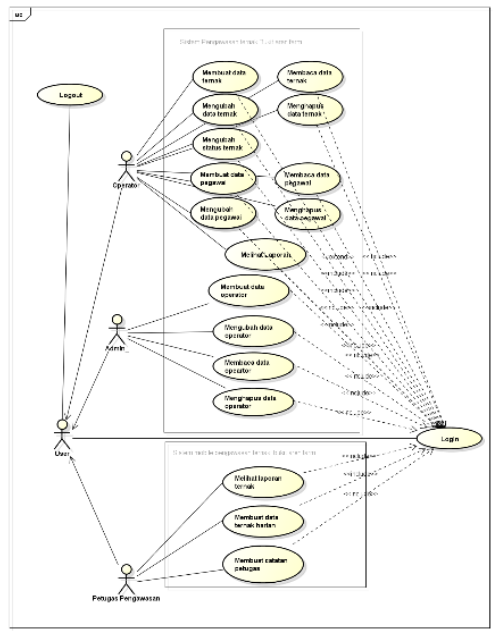

Gambar 4 Diagram Use Case Sistem

Pemodelan diagram use case menunjukkan bahwa sistem terdapat 3 aktor yang menggunakan sistem. Sistem memiliki sembilan belas skenario umum.

3. Diagram kelas

Diagram kelas pada gambar 5 menunjukkan kelas dengan atribut yang saling terhubung dengan kelas lain.

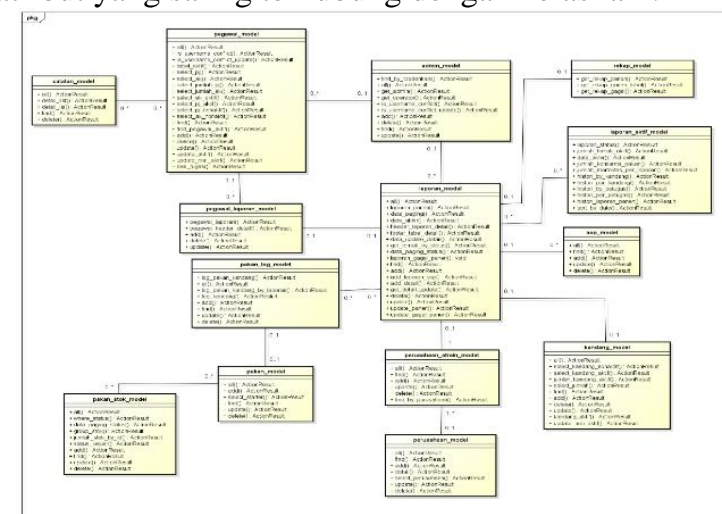

Gambar 5 Diagram kelas tipe model keseluruhan sistem
Kelas yang ada pada Gambar 5 tersebut merupakan kelas dengan tipe model yang berfungsi sebagai abstraksi basis data. Semua model yang ada merupakan extend dari active record yang berfungsi sebagai penghubung dengan kelas tipe controller.

Diagram kelas pada gambar 6 menunjukkan kelas controller yang berfungsi sebagai pengolah Business logic.

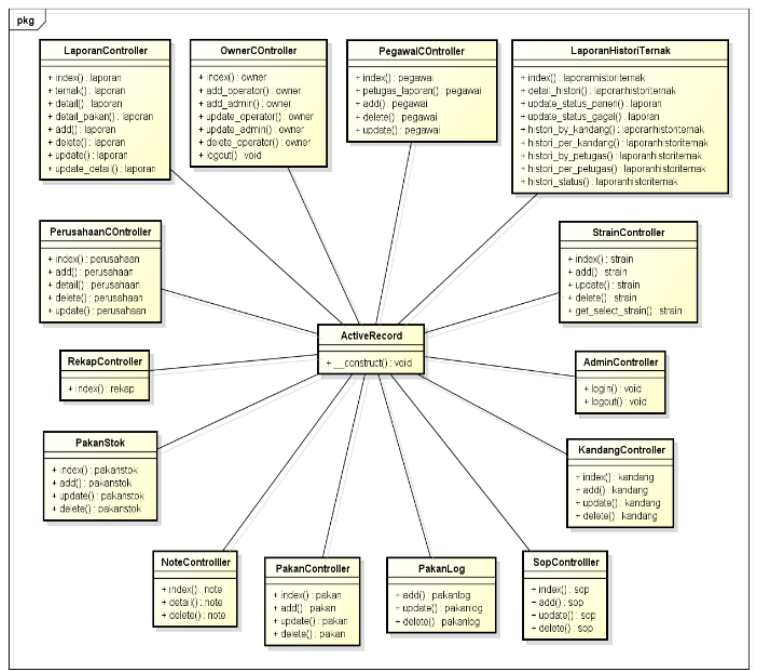

Gambar 6 Diagram kelas tipe controller keseluruhan sistem

Kelas controller dapat berinteraksi dengan data di dalam basis data dengan Repository Pattern. Deskripsi masing masing kelas ditunjukkan pada tabel 2.

Tabel 2 Deskripsi diagram kelas

\begin{tabular}{|l|l|l|}
\hline No & Kelas & Deskripsi \\
\hline 1 & Admin_model & Model data pengguna admin \\
\hline 2 & Catatan_model & Model data catatan pegawai \\
\hline 3 & Kandang_model & Model data kandang \\
\hline 4 & Laporan_model & Model data laporan ternak \\
\hline 5 & $\begin{array}{l}\text { Laporan_aktif_mo } \\
\text { del }\end{array}$ & Model data laporan aktif \\
\hline 6 & Pakan_model & Model data pakan \\
\hline 7 & Pakan_log_model & Model data log pakan \\
\hline 8 & Pakan_stok_model & Model data stok pakan \\
\hline 9 & Pegawai_model & Model data pegawai \\
\hline 10 & $\begin{array}{l}\text { Pegawai_laporan__ } \\
\text { model }\end{array}$ & Model data pegawai laporan \\
\hline 11 & Perusahaan_model & Model data perusahaan doc \\
\hline 12 & $\begin{array}{l}\text { Perusahaan_strain } \\
\text { model }\end{array}$ & $\begin{array}{l}\text { Model data perusahaan strain } \\
\text { doc }\end{array}$ \\
\hline 13 & Rekap_model & Model data rekap laporan \\
\hline 14 & Sop_model & Model data sop ternak \\
\hline 15 & ActiveRecord & $\begin{array}{l}\text { Kelas yang digunakan oleh } \\
\text { controller untuk mengakses } \\
\text { model }\end{array}$ \\
\hline 16 & AdminController & $\begin{array}{l}\text { Controller yang mengelola data } \\
\text { operator }\end{array}$ \\
\hline 17 & KandangController & $\begin{array}{l}\text { Controller yang mengelola data } \\
\text { kandang }\end{array}$ \\
\hline 18 & LaporanController & $\begin{array}{l}\text { Controller yang mengelola data } \\
\text { laporan ternak } \\
\text { Controller yang mengelola data } \\
\text { histori ternak }\end{array}$ \\
\hline 19 & $\begin{array}{l}\text { LaporanHistoriTer } \\
\text { nak }\end{array}$ & $\begin{array}{l}\text { Controller yang mengelola data } \\
\text { catatan pegawai }\end{array}$ \\
\hline 20 & NoteController \\
\hline 21 & OwnerController & $\begin{array}{l}\text { Controller yang mengelola data } \\
\text { admin }\end{array}$ \\
\hline
\end{tabular}




\begin{tabular}{|c|l|l|}
\hline 22 & PakanController & $\begin{array}{l}\text { Controller yang mengelola data } \\
\text { pakan }\end{array}$ \\
\hline 23 & PakanLog & $\begin{array}{l}\text { Controller yang mengelola data } \\
\text { log pakan }\end{array}$ \\
\hline 24 & PakanStok & $\begin{array}{l}\text { Controller yang mengelola data } \\
\text { stok pakan }\end{array}$ \\
\hline 25 & $\begin{array}{l}\text { PerusahaanControl } \\
\text { ler }\end{array}$ & $\begin{array}{l}\text { Controller yang mengelola data } \\
\text { perusahaan }\end{array}$ \\
\hline 26 & PegawaiController & $\begin{array}{l}\text { Controller yang mengelola data } \\
\text { pegawai }\end{array}$ \\
\hline 27 & RekapController & $\begin{array}{l}\text { Controller yang mengelola data } \\
\text { rekap laporan }\end{array}$ \\
\hline 28 & SopController & $\begin{array}{l}\text { Controller yang mengelola data } \\
\text { sop }\end{array}$ \\
\hline 29 & StrainController & $\begin{array}{l}\text { Controller yang mengelola data } \\
\text { strain doc }\end{array}$ \\
\hline
\end{tabular}

Pemodelan yang dibuat sudah cukup untuk digunakan menjelaskan bagaimana sistem akan memenuhi kebutuhan sistem. Diagram aktivitas memberikan gambaran utama bagaimana sistem akan digunakan dalam proses bisnis. Diagram use case memberikan informasi bagaimana pengguna menggunakan sistem. Diagram sequence menampilkan perilaku sistem ketika digunakan pengguna. Diagram kelas menunjukkan struktur sistem.

Kode yang digunakan untuk membangun aplikasi bisa dikerjakan setelah tahap ini. Spesifikasi teknis dan pemodelan dapat memberikan gambaran dan arahan bagaimana kode ditulis. Penulisan kode kemudian dikerjakan hingga selesai.

\section{PENGUJiAn SisteM}

Pengujian integrasi dilakukan untuk mengetahui apakah setiap fungsi yang dimiliki sistem mampu saling terhubung untuk melakukan pekerjaan utama. Pengujian dilakukan karena kesalahan dalam sistem mungkin terjadi walaupun masing masing fungsi telah diuji. Kesalahan seperti itu umumnya terjadi karena fungsi yang ada tidak terhubung atau tidak memiliki batasan yang sama dengan fungsi lainnya. Pengguna mengeksekusi banyak fungsi dalam melakukan pekerjaannya. Hubungan antar fungsi tersebut adalah bentuk integrasi unit. Skenario buatan atau simulasi pekerjaan dilakukan untuk menjalankan pengujian integrasi. Skenario yang dilakukan pada pengujian ini adalah sebagai berikut :

1. Membuat Data Ternak

Petugas Operator membuat data ternak baru dan petugas dengan nama rahmat sebagai penanggung jawab dari laporan ternak yang telah dibuat. Tampilan pembuatan data ternak baru ditunjukkan pada Gambar 7.

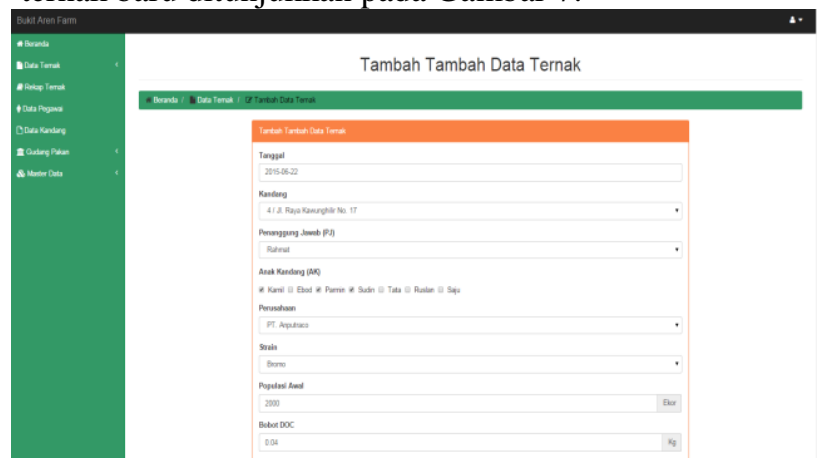

Gambar 7 Pengujian integrasi membuat data ternak

Data ternak baru yang dibuat oleh operator menjadi data ternak yang akan dilakukan pengawasan ternak oleh petugas pengawasan sesuai dengan data ternak yang telah dibuat.

\section{Petugas Pengawasan Ternak Melakukan Login}

Petugas Pengawasan ternak mendapatkan akun dari operator yang dapat digunakan untuk melakukan kegiatan login untuk dapat menggunakan fitur pada aplikasi pengawasan ternak diantaranya melakukan pencatatan data ternak harian, melihat data ternak, dan menulis catatan ternak. Gambar 8 menunjukan proses login oleh petugas pengawas



Gambar 8 Pengujian integrasi aktivitas login

3. Petugas Pengawasan memasukan data ternak harian

Petugas dapat melakukan kegiatan memasukan data ternak harian dengan melakukan pemindaian qr-code sesuai dengan data ternak pengawasan petugas tersebut, hal ini sekaligus sebagai proses otentifikasi petugas pengawasan ketika memasukan data ternak.

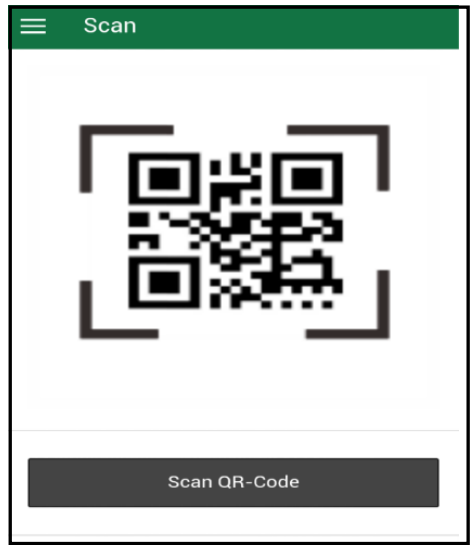

Gambar 9 Pengujian integrasi pemindai qr code

Untuk melakukan aktivitas memasukan data ternak harian terlebih dahulu ditampilkan informasi data ternak.

Gambar 10 menunjukkan informasi data ternak.

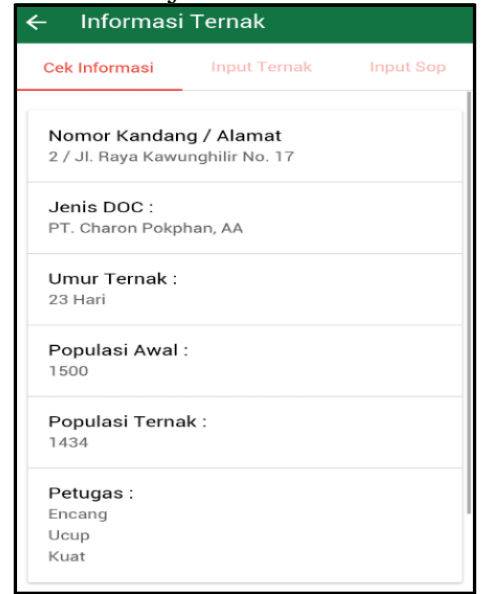

Gambar 10 Pengujian integrasi menampilkan data ternak 
Untuk memasukkan data ternak harian tekan lanjut. Gambar 11 aktivitas memasukan data ternak harian.

\begin{tabular}{|c|c|c|c|}
\hline \multicolumn{4}{|c|}{$\leftarrow \quad$ Input data ternak } \\
\hline Cek Informasi & Input Ternak & \multicolumn{2}{|c|}{ Input Sop } \\
\hline \multicolumn{4}{|l|}{ Tanggal } \\
\hline \multicolumn{4}{|c|}{ Kematian (1415) } \\
\hline \multicolumn{4}{|l|}{12} \\
\hline \multicolumn{4}{|c|}{ Kandang Karantina (1422) } \\
\hline \multicolumn{4}{|l|}{19} \\
\hline \multicolumn{4}{|l|}{ Bobot } \\
\hline \multicolumn{4}{|l|}{0.8} \\
\hline Pakan & Star & 3R-11 & $\checkmark$ \\
\hline \multicolumn{3}{|l|}{250 이 } & \\
\hline & Lanjut & & \\
\hline
\end{tabular}

Gambar 11 Pengujian integrasi menampilkan data ternak

Setelah petugas pengawasan ternak mengisi form data ternak harian, petugas dapat memilih daftar sop ternak yang sudah dikerjakan kemudian menekan tombol simpan. Gambar 12 konfirmasi memasukkan data ternak harian.

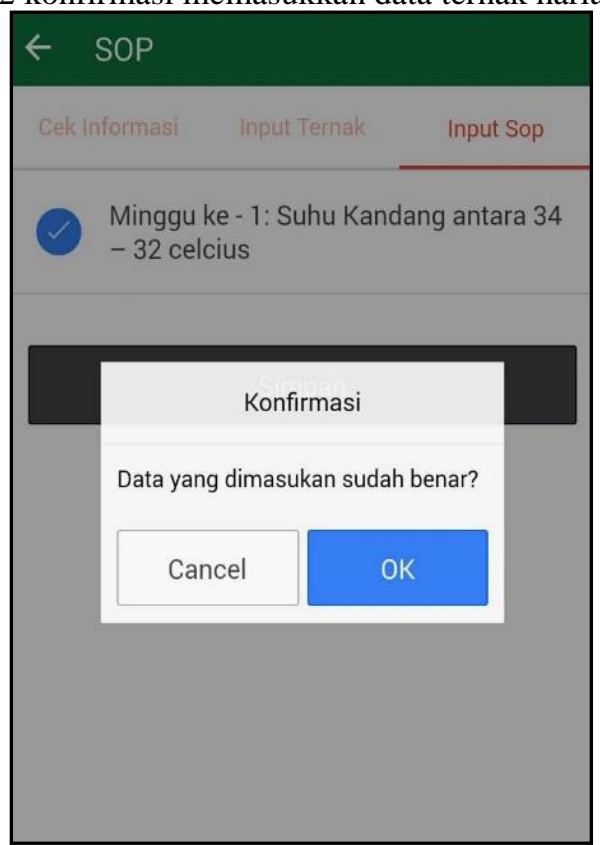

Gambar 12 Pengujian integrasi konfimrasi memasukan data ternak harian

4. Petugas Pengawasan melihat laporan ternak

Proses pencatatan dari aktivitas pengawasan ternak yang telah dilakukan dapat dilihat pada menu lihat laporan. Informasi yang ditampilkan ditampilkan dalam informasi detail ternak, informasi populasi ternak, informasi pakan ternak dan informasi sop ternak. Gambar 13 menunjukkan informasi laporan ternak.

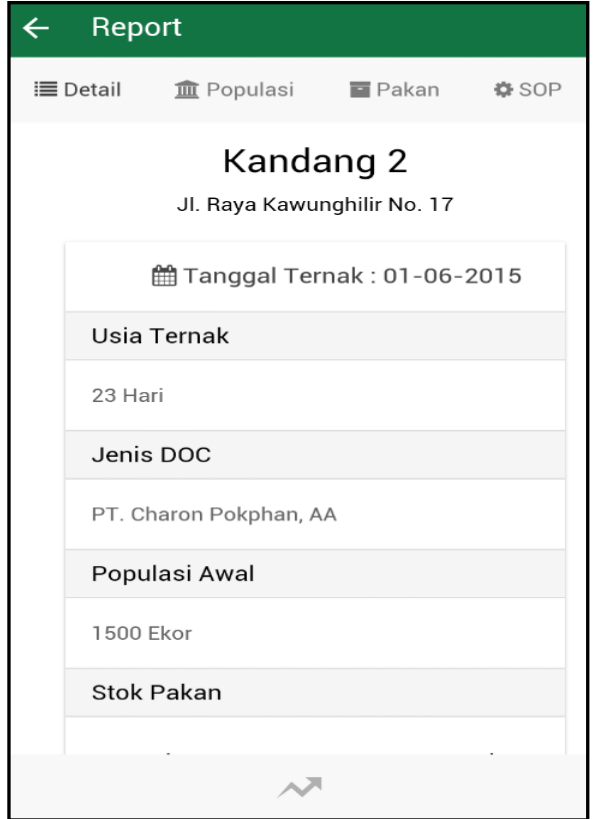

Gambar 13 Pengujian integrasi konfirmasi pembayaran

5. Petugas membuat catatan ternak

Petugas dapat membuat catatan ternak yang bertujuan agar petugas dapat menyimpan informasi selama melakukan aktivitas ternak selain itu sekaligus memberi tahu operator mengenai informasi tersebut. Gambar 14 menunjukkan aktivitas membuat catatan.

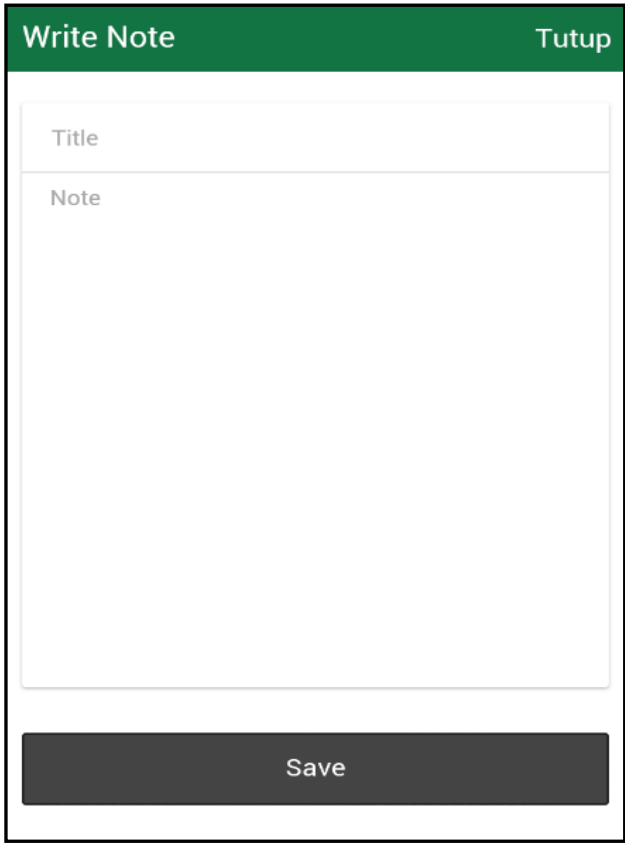

Gambar 14 Pengujian integrasi mengubah status pesanan

6. Operator pengawasan ternak bukit aren farm merubah status ternak

Operator pengawasan ternak dapat melakukan perubahan status ternak. Gambar 15 menunjukkan laporan ternak yang akan diubah statusnya. 


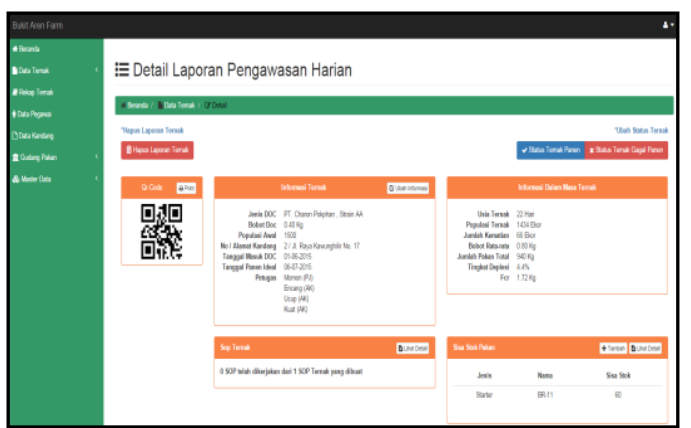

Gambar 15 Pengujian integrasi membaca riwayat pemesanan

Lima skenario yang dijalankan menjelaskan bahwa sistem dapat mengintegrasikan unit dalam sistem untuk melakukan pekerjaan. Skenario yang diuji ditampilkan detail dengan fungsi terkait pada tabel 3 .

Tabel 3 Hasil skenario pengujian integrasi

\begin{tabular}{|l|l|l|}
\hline Skenario & Fungsi Terkait & Analisis \\
\hline Ternak & $\begin{array}{l}\text { Login, membuat data ternak } \\
\text { baru }\end{array}$ & Berhasil \\
\hline $\begin{array}{l}\text { Petugas } \\
\text { melakukan login }\end{array}$ & $\begin{array}{l}\text { Login, memasukan } \\
\text { username dan password }\end{array}$ & Berhasil \\
\hline $\begin{array}{l}\text { Petugas } \\
\text { melakukan data } \\
\text { ternak harian }\end{array}$ & $\begin{array}{l}\text { Login, melakukan scan qr- } \\
\text { code, melakukan } \\
\text { pengecekan informasi, } \\
\text { memasukan informasi } \\
\text { ternak, memilih sop ternak } \\
\text { yang dilakukan }\end{array}$ & Berhasil \\
\hline $\begin{array}{l}\text { Petugas melihat } \\
\text { laporan ternak }\end{array}$ & $\begin{array}{l}\text { Login, melihat laporan } \\
\text { ternak berupa informasi } \\
\text { detail ternak, informasi } \\
\text { populasi ternak, informasi } \\
\text { pakan, informasi sop, dan } \\
\text { informasi hasil ternak } \\
\text { dalam bentuk grafik }\end{array}$ & Berhasil \\
\hline $\begin{array}{l}\text { Petugas membuat } \\
\text { catatan ternak }\end{array}$ & $\begin{array}{l}\text { Login, membuat catatan } \\
\text { ternak }\end{array}$ & Berhasil \\
\hline $\begin{array}{l}\text { Operator } \\
\text { pengawasan } \\
\text { Farnak Bukit Aren }\end{array}$ & $\begin{array}{l}\text { Login, membaca data } \\
\text { ternak, merubah status } \\
\text { ternak }\end{array}$ & Berhasil \\
\hline
\end{tabular}

Tahap pengujian yang dilakukan menunjukkan sistem memiliki fungsi yang bekerja dengan benar.

\section{PENUTUP}

\section{A Kesimpulan}

Selama pengembangan sistem ini terdapat beberapa hal yang bisa disimpulkan. Kesimpulan yang didapatkan antara lain:

1. Aplikasi mobile pengawasan ternak dapat mengolah data ternak dengan risiko data hilang atau rusak lebih kecil daripada metode sebelumnya.

2. Sistem yang dikembangkan dapat mengolah data masukan ternak, sehingga dapat mengurangi ketidakcocokan data ternak yang diolah dibandingkan metode konvensional.

3. Aplikasi mobile pengawasan ternak menggunakan QR Code sebagai otentifikasi dalam proses memasukan data ternak harian.

4. Sistem yang dikembangkan dapat menampilkan data ternak per periode atau rentang waktu tertentu untuk kemudian dibuat menjadi laporan ternak.
5. Sistem yang dikembangkan dapat memfasilitasi kegiatan pengawasan ternak oleh petugas pengawasan ternak sesuai kebutuhan peternakan Bukit Aren Farm.

B Saran

1. Sistem informasi ini memiliki banyak ruang untuk dikembangkan seperti integrasi dengan sistem manajemen kesehatan ternak.

2. Fitur pendeteksi penyakit pada sistem manajemen kesehatan ternak belum bisa diimplementasikan karena dibutuhkan perancangan dan pengembangan sistem yang berbeda.

\section{DAFTAR PUSTAKA}

[1] M. R. Fatoni, "RANCANG BANGUN SISTEM INFORMASI PEMANTAUAN PERKEMBANGAN AYAM BROILER (Studi kasus di PS. Bintang Unggas Lamongan)," 2011.

[2] C. Mulyadi, "SISTEM INFORMASI PETERNAKAN AYAM POTONG BERBASIS WEB," 2011.

[3] S. Alter, The Work System Method: Connecting People, Processes, and IT for Business Results, CA: Works System Press, 2006.

[4] Fathansyah, Basis Data, Bandung: Informatika, 2012.

[5] W. Komputer, Mudah membuat Aplikasi SMS Gateway dengan CodeIgniter, Jakarta: Elex Media Komputindo, 2014.

[6] driftyco, "What is Ionic," 2014. [Online]. Available: https://github.com/driftyco/ionic. [Diakses 1710 2014].

[7] W. Willard, HTML: A Beginner's Guide, California: McGraw-Hill Osborne Media, 2013.

[8] A. Taufik, Pemrograman Grafik dengan Java, Bandung: Informatika, 2010.

[9] R. Tantra, Manajemen Proyek Sistem Informasi, Yogyakarta: ANDI, 2012.

[10] A. S. Rosa dan M. Shalahuddin, Modul Pembelajaran Rekayasa Perangkat Lunak (Terstruktur dan Berorientasi Objek), Bandung: Modula, 2011.

[11] R. Pressman, 2012, Yogyakarta: ANDI, Rekayasa Perangkat Lunak.

[12] OMG, "UML Infrastructure Specification, v2.4.1," 2011. [Online].

Available: http://www.omg.org/spec/UML/2.4.1/Infrastructure/PDF/.

[13] D. P. Oktavian, Membuat Web Powerfull Menggunakan PHP, Yogyakarta: Mediakom, 2013.

[14] R. Lerdorf, K. Tatroe dan P. MacIntyre, Programming PHP, California: O'Reilly Media, Inc, 2006.

[15] M. Huda dan B. Komputer, Membuat Aplikasi Database Dengan Java, MySql dan NetBeans, Jakarta: Elex Media Komputindo, 2010.

[16] B. K. Hamilton dan R. Miles, Learning UML 2.0, California: O’Reilly Media, Inc, 2006.

[17] W. Hales, HTML5 and JavaScript Web Apps, California: O'Reilly Media, Inc, 2013.

[18] A. Freeman, Pro ASP. NET MVC 5, New York: Apress, 2013.

[19] R. Earp dan S. Bagui, Database Design Using EntityRelationship Diagrams, Florida: Auerbach, 2003. 